\title{
Chloroplast analysis of Zelkova schneideriana (Ulmaceae): genetic diversity, population structure, and conservation implications
}

\author{
H.L. Liu', ${ }^{1,2}$, R.Q. Zhang ${ }^{2}$, M.L. Geng ${ }^{3}$, J.Y. Zhu' ${ }^{1}$, J.C. An ${ }^{1}$ and J.L. Ma ${ }^{1}$ \\ ${ }^{1}$ Guangxi Forestry Research Institute, Nanning, Guangxi, China \\ ${ }^{2}$ College of Forestry, Central South University of Forestry and Technology, \\ Changsha, Hunan, China \\ ${ }^{3}$ Institute of Botany, Jiangsu Province and Chinese Academy of Sciences, Nanjing, \\ Jiangsu, China \\ Corresponding authors: R.Q. Zhang / J.C. An \\ E-mail: hanszhangriqing@csuft.edu.cn / anjiachenglz@163.com \\ Genet. Mol. Res. 15 (1): gmr.15017739 \\ Received September 28, 2015 \\ Accepted December 7, 2015 \\ Published February 19, 2016 \\ DOI http://dx.doi.org/10.4238/gmr.15017739
}

\begin{abstract}
Zelkova schneideriana is endemic to China and belongs to the Ulmaceae. It is listed as a Near Threatened species in the China Biodiversity Red Data Book. We conducted a phylogeographical study of two chloroplast regions ( $p s b \mathrm{~A}-t r n \mathrm{H}$ and trnG-trnM) in several Chinese $Z$. schneideriana populations, in order to examine the genetic diversity, population structure, and evolutionary history of the species. In all, 10 haplotypes were detected. The population from Sangzhi, Hunan, had the highest nucleotide diversity $(\pi=0.00653)$ and haplotype diversity $\left(H_{\mathrm{D}}\right.$ $=1.000$ ), and should be considered the most suitable population to be protected under an in situ conservation strategy. Seed collections from as many individuals as possible in other populations would preserve the genetic diversity of $Z$. schneideriana.
\end{abstract}

Key words: Zelkova schneideriana (Ulmaceae); Chloroplast analysis; Genetic diversity; Population structure; Conservation implications 


\section{INTRODUCTION}

Zelkova (Ulmaceae) is a small genus that comprises six tree species (Denk and Grimm, 2005) that belong to the Tertiary tree flora (Garfi, 1997). Zelkova schneideriana Hand.-Mazz. is a deciduous hardwood species that is categorized as Near Threatened (NT) in the Chinese Biodiversity Red Data Book (Environmental Protection Department and Chinese Academy of Sciences, 2013), and has significant ecological and commercial importance (Cao et al., 2005; Zhang et al., 2011). It is cultivated and highly valued in China, Korea, Japan, and other East Asian countries; however, it has become a rare and endangered species in the wild in China due to uncontrolled, commercial logging and a lack of effective propagation methods (Fu and Jin, 1992). Therefore, the current status of $Z$. schneideriana requires the development of effective conservation and management strategies to protect this important germplasm resource. As a consequence of industrial production, cultivated plants suffer from genetic erosion that could result in a loss of genetic diversity and important traits, including resistance to pathogens. In contrast, wild species generally exhibit abundant genetic diversity, and may serve as valuable genetic resources for the genetic improvement of cultivated plants.

Genetic diversity and population structure are critical factors for the long-term survival of a species, including its adaptation to environmental change (Taberlet et al., 1998), and play a pivotal role in the conservation and management of wild species by identifying which populations should be given priority for protection (Newton et al., 1999). Most previous study has focused on the breeding and cultivation of this species, and little has been conducted to evaluate the genetic diversity and population structure of $Z$. schneideriana, except by using inter-simple sequence repeat (ISSR) markers in small populations (Liu et al., 2005).

Chloroplast DNA (cpDNA) is a maternally inherited marker that undergoes little or no recombination, and exhibits a high level of genetic diversity and significant population structure (Clegg and Zurawski, 1992; Petit et al., 1993, 2005). Therefore, in this study, cpDNA haplotypes were used to study the genetic diversity of $Z$. schneideriana, in order to provide the data needed for developing rational and scientific conservation and management strategies for this species.

\section{MATERIAL AND METHODS}

\section{Plant materials}

Z. schneideriana is diploid $(2 \mathrm{n}=2 \mathrm{X}=28)$ ( He and Jin, 2005). Individual trees are monoecious, having both male and female flowers on a single tree (Denk and Grimm, 2005). Silicadried leaf materials of 12 populations and 144 individuals were collected, including two populations from America and Australia (Table 1).

\section{DNA extraction, polymerase chain reaction (PCR) amplification, and cpDNA sequencing}

Total genomic DNA extraction was performed with a modified CTAB method as described by Doyle (1991). DNA quality was checked by monitoring the absorption ratio $A_{260} / A_{280}\left(O D_{260} /\right.$ $\mathrm{OD}_{280}$ ) and on agarose gel; the concentration was calculated and adjusted to $10-30 \mathrm{ng} / \mathrm{mL}$. 


Table 1. Sampling details of Zelkova schneideriana.
\begin{tabular}{l|c|c}
\hline Location & No. of individuals & Population code \\
\hline Nanjing, Jiangsu & 6 & JR \\
\hline Jurong, Jiangsu & 9 & TX \\
\hline Tongxiang, Zhejiang & 8 & HN \\
\hline Haining, Zhejiang & 8 & CZ \\
\hline Chuzhou, Anhui & 23 & GZ \\
\hline Ganzhou, Jiangxi & 8 & HH \\
\hline Huaihua, Hu'nan & 10 & CB \\
\hline Chengbu, Hu'nan & 5 & WH \\
\hline Sangzhi, Hu'nan & 18 & AM \\
\hline Wuhan, Hubei & 14 & AS \\
\hline USA & 14 & \\
\hline Australia & & \\
\hline
\end{tabular}

Fifteen primers were preliminarily screened and sequenced in order to identify well-amplified bands, which were stable and highly polymorphic loci in five individuals from five geographically distinct populations of $Z$. schneideriana. Two highly polymorphic regions, psbA-trnH and trnM-G intergenic spacers, were selected and sequenced. $p s b A-t r n \mathrm{H}$ was amplified using the primer pair psbA (5'-GTTATGCATGAACGTAATGCTC-3') and trnH (5'-CGCGCATGGTGGATTCACAATCC3') (Kress et al., 2005). The trnM-G intergenic spacer primer was designed in this study (F, 5'-TAGCGGGAGGGGTCAAAC-3'; R, 5'-GCTCGCAAGGCTCATAAC-3'). Each PCR amplification was conducted in a $50-\mu \mathrm{L}$ volume containing $50 \mathrm{ng}$ DNA template, $0.4 \mathrm{mM}$ of each primer, $200 \mathrm{mM}$ of each dNTP, $2 \mathrm{mM} \mathrm{MgCl}_{2}$, and $2 \mathrm{U}$ rTaq DNA polymerase (TaKaRa, Dalian, China). Amplifications were performed with the following cycling conditions: $95^{\circ} \mathrm{C}$ for $5 \mathrm{~min}, 35$ cycles at $94^{\circ} \mathrm{C}$ for $30 \mathrm{~s}$, $55^{\circ} \mathrm{C}$ for $30 \mathrm{~s}, 72^{\circ} \mathrm{C}$ for $1 \mathrm{~min}$, and a final extension cycle for $10 \mathrm{~min}$ at $72^{\circ} \mathrm{C}$.

The size of the PCR products was determined electrophoretically on $1 \%(\mathrm{w} / \mathrm{v})$ agarose gels run at $120 \mathrm{~V}$ in $0.5 \mathrm{X}$ TBE buffer, and visualized by staining with ethidium bromide. All of the PCR products were purified from $1.5 \%$ (w/v) agarose gels using an AxyPrep ${ }^{T w}$ DNA Gel Extraction Kit (Axygen, Hangzhou, China), and directly sequenced using an ABI 3730 DNA Sequencer (Applied Biosystems, Foster City, CA, USA).

\section{Data analyses}

The raw-sequence cpDNA intergenic regions were edited by Sequencher 4.5 (Gene Coding, Ann Arbor, MI, USA), and aligned using Geneious (Drummond et al., 2010) that was manually adjusted. All of the sequences were saved in FASTA format for further analyses after being manually refined. Indels were included and treated as single-mutation events, and coded separately as binary states that were coded as substitutions ( $A$ or $T$ ), because 1 and 0 are not accepted by TCS 1.21 (Clement et al., 2000), the program that we used for network construction. The network was rooted on Z. serrata as an outgroup, and the geographical distribution of haplotypes was plotted on a map using Adobe Illustrator (Adobe Inc.).

To measure levels of genetic variation, haplotype number, haplotype diversity $\left(H_{D}\right)$, 
nucleotide diversity $(\pi)$ (Nei et al., 1983), and genetic differentiation between populations $\left(G_{S T}\right)$ were calculated using DNASP 5.10.01 (Librado and Rozas, 2009). A statistical parsimony network of cpDNA haplotypes was constructed using TCS 1.21, which connected the haplotypes with a probability of $>95 \%$. The Mantel test and molecular analysis of variance (AMOVA) (Excoffier et al., 1992) were performed using Arlequin 3.0 (Excoffier et al., 2005). Gene flow $\left(N_{\mathrm{m}}\right)$ between the haplotypes was calculated by $F_{\mathrm{ST}}=1 /\left(1+2 N_{\mathrm{m}}\right)($ Wright, 1949). A neighbor-joining phylogenetic tree that depicted relationships between the haplotypes was constructed using MEGA 5.0, according to Kimura's two-parameter model (Kimura, 1980).

\section{RESULTS}

\section{Sequence characteristics of the two chloroplast intergenic spacers}

The psbA-trn $\mathrm{H}$ and trnM-trnG intergenic spacers were aligned into 398 and $608 \mathrm{bp}$, respectively. Nine psbA-trnH (GenBank accession Nos. KM288595-KM288603) and five trnMtrnG (KM288604-KM288608) haplotypes were identified among the individuals, resulting in 10 haplotypes (H1-10) over the combined cpDNA sequences (1006 bp) that contained 19 varieties, including five substitutions and 14 indels (Table 2).

Table 2. Distribution of psbA-trnH and trnM-trnG polymorphic sites in 10 haplotypes ( $\mathrm{H} 1-10)$ of Zelkova schneideriana.

\begin{tabular}{|c|c|c|c|c|c|c|c|c|c|c|c|c|c|c|c|c|c|c|c|}
\hline \multirow{5}{*}{ Haplotype } & \multicolumn{19}{|c|}{ Polymorphic nucleotide position } \\
\hline & \multicolumn{10}{|c|}{ psbA-trnH } & \multicolumn{9}{|c|}{ 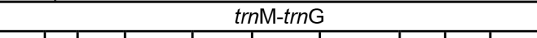 } \\
\hline & 1 & 1 & 1 & 1 & 2 & 2 & 2 & 2 & 2 & 2 & 3 & 4 & 5 & 5 & 7 & 7 & 7 & 8 & 8 \\
\hline & 4 & 4 & 6 & 8 & 0 & 7 & 7 & 7 & 8 & 9 & 2 & 5 & 5 & 7 & 2 & 5 & 5 & 0 & 8 \\
\hline & 2 & 6 & 4 & 2 & 0 & 2 & 4 & 7 & 1 & 7 & 8 & 0 & 6 & 2 & 8 & 4 & 7 & 6 & 4 \\
\hline $\mathrm{H} 1$ & $T$ & $1^{\mathrm{a}}$ & 0 & 0 & $1^{\mathrm{c}}$ & A & $T$ & $1^{e}$ & $1^{f}$ & 0 & 0 & 0 & $\mathrm{j}^{\mathrm{j}}$ & $1^{\mathrm{k}}$ & $1^{\prime}$ & 0 & $\mathrm{~T}$ & $\mathrm{~T}$ & $1^{n}$ \\
\hline $\mathrm{H} 2$ & & $1^{\mathrm{a}}$ & 0 & 0 & 0 & & & 0 & 0 & 0 & 0 & 0 & ij $^{\mathrm{j}}$ & $1^{\mathrm{k}}$ & $1^{\prime}$ & 0 & 0 & 0 & $1^{n}$ \\
\hline $\mathrm{H} 3$ & & $1^{\mathrm{a}}$ & 0 & 0 & 0 & & A & $1^{\mathrm{e}}$ & $1^{f}$ & 0 & 0 & 0 & $1^{\mathrm{j}}$ & $1^{\mathrm{k}}$ & $1^{\prime}$ & 0 & 0 & 0 & $1^{n}$ \\
\hline $\mathrm{H} 4$ & & $1^{\mathrm{a}}$ & 0 & $1^{c}$ & $1^{\mathrm{d}}$ & - & & $1^{\mathrm{e}}$ & $1^{f}$ & 19 & 0 & 0 & $1^{\mathrm{j}}$ & $1^{\mathrm{k}}$ & $1^{\prime}$ & 0 & 0 & 0 & $1^{n}$ \\
\hline $\mathrm{H} 5$ & . & $1^{\mathrm{a}}$ & $1^{b}$ & $1^{c}$ & $1^{\mathrm{d}}$ &. &. & $1^{\mathrm{e}}$ & $1^{f}$ & 19 & 0 & 0 & $1 j$ & $1^{\mathrm{k}}$ & $1^{\prime}$ & 0 & 0 & 0 & $1^{n}$ \\
\hline $\mathrm{H} 6$ & A & $1^{\mathrm{a}}$ & 0 & 0 & 0 & $\mathrm{~T}$ & A & 0 & 0 & 0 & 0 & $1^{i}$ & $1^{j}$ & 0 & $1^{\prime}$ & $1^{m}$ & $\mathrm{~T}$ & 0 & $1^{n}$ \\
\hline $\mathrm{H} 7$ & & $1^{a}$ & 0 & 0 & 0 & $\mathrm{~T}$ & A & 0 & 0 & 0 & 0 & $1^{i}$ & $1^{\mathrm{j}}$ & 0 & $1^{1}$ & $1^{\mathrm{m}}$ & $T$ & 0 & $1^{n}$ \\
\hline $\mathrm{H} 8$ & - & $1^{\mathrm{a}}$ & 0 & 0 & 0 & 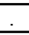 & $A$ & $1^{\mathrm{e}}$ & $1^{f}$ & 0 & 0 & 0 & $1^{j}$ & 0 & $1^{1}$ & $1^{m}$ & $T$ & 0 & $1^{n}$ \\
\hline $\mathrm{H} 9$ & . & 0 & 0 & 0 & 0 & & 0 & $1^{\mathrm{e}}$ & 0 & 0 & $1^{\text {h }}$ & $1^{i}$ & 0 & $1^{\mathrm{k}}$ & 0 & $1^{\mathrm{m}}$ & $T$ & 0 & 0 \\
\hline $\mathrm{H} 10$ & & $1^{a}$ & 0 & 0 & 0 & . & & $1^{\mathrm{e}}$ & $1^{f}$ & 0 & 0 & 0 & $1^{j}$ & $1^{\mathrm{k}}$ & $1^{\prime}$ & 0 & 0 & 0 & $1^{n}$ \\
\hline
\end{tabular}

Dots denote a base identical to haplotype $1(\mathrm{H} 1) ; 0 / 1$ indicates the absence/ presence of indels. 'AATAATATTATTT; ' 'TTATTTAATATTTATTAG; '

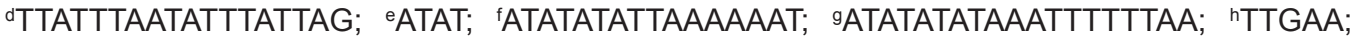
'ATTTAATTAATTACCGTTTTT; 'TATCCTA; kTTAAAT; 'CAGAGCTA; mTTT; ' ${ }^{\text {TATTAT. }}$

\section{Haplotype network and distribution}

The haplotype network (Figure 1) was dominated by haplotype $\mathrm{H} 4$, which was found in nine populations $(9 / 12,75 \%)$ and 60 individuals (60/144, 41.67\%). Haplotypes H3 and H8 were the most interior haplotypes, and were mutationally closer to the outgroup sequence of $Z$. serrata. Accordingly, these haplotypes were identified as the ancestral types of numerous tip haplotypes 
(Figure 1A). As shown in Table 3 and Figure 1B, some haplotypes were found to be unique to certain populations: $\mathrm{H} 5$ was only found in the AM population, $\mathrm{H} 7$ in the $\mathrm{HN}$ population, $\mathrm{H} 9$ in the JR population, and $\mathrm{H} 10$ in the TX population.

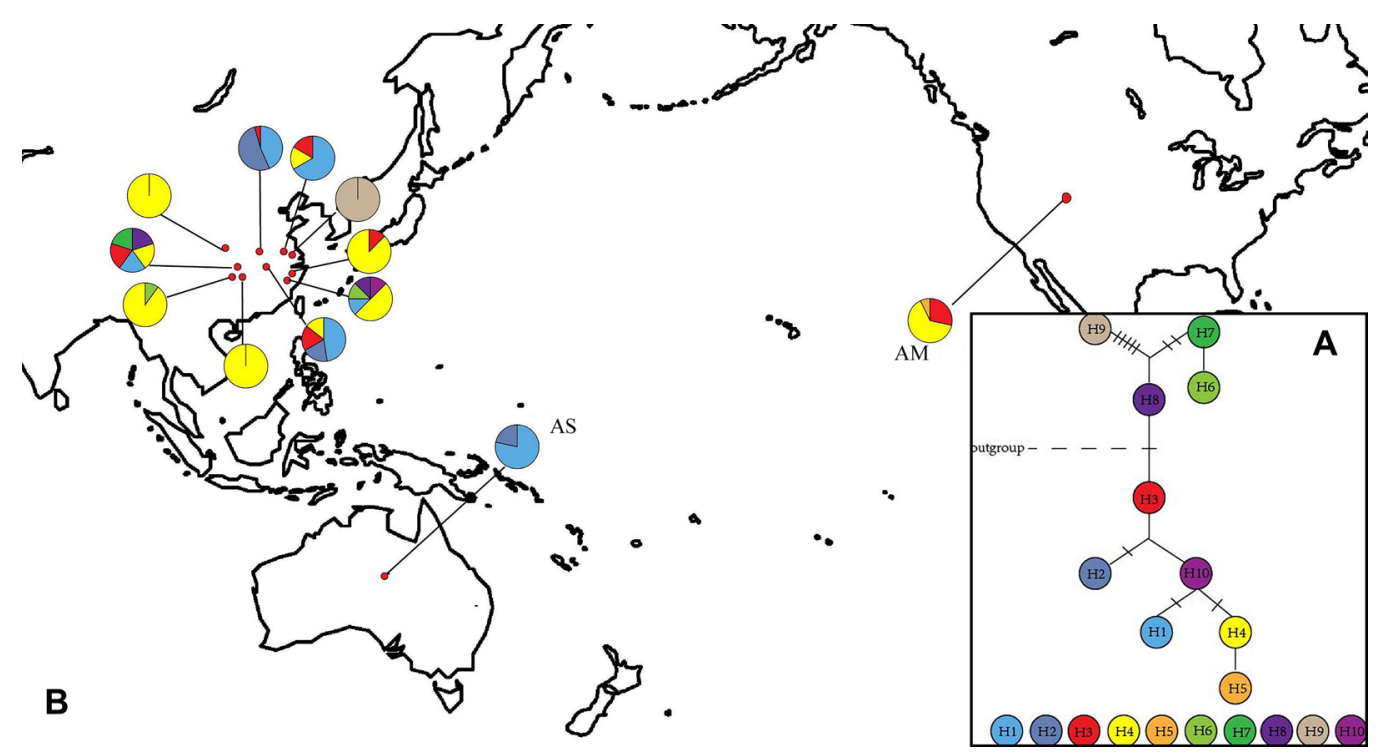

Figure 1. Phylogeographical relationships between $10 \mathrm{cpDNA}$ haplotypes $(\mathrm{H} 1-10)$ found in a sequence analysis of the psbA-trnH and trnM-trnG regions of Zelkova schneideriana. A. Statistical parsimony network of haplotypes, in which circle sizes are proportional to the frequency of each haplotype. Each solid line connecting haplotypes represents a single mutation. The oblique line indicates hypothetical missing haplotypes (i.e., extinct or not sampled). The dotted line indicates the outgroup. B. Geographical distribution of cpDNA haplotypes detected in Z. schneideriana. Each circle indicates one population. Single-haplotype circles represent monomorphic populations; circles with two to five divisions indicate the proportions of different haplotypes detected in a given population (Table 3).

Table 3. Haplotype diversity, nucleotide diversity, and haplotype frequency in each population.

\begin{tabular}{|c|c|c|c|c|c|}
\hline Region & Location & $\begin{array}{l}\text { Population } \\
\text { code }\end{array}$ & $\begin{array}{c}\text { Haplotype diversity } \\
\left(H_{D}\right)\end{array}$ & $\begin{array}{c}\text { Nucleotide diversity } \\
\pi\left(\times 10^{-3}\right)\end{array}$ & $\begin{array}{l}\text { Haplotypes } \\
\text { (No. of individuals) }\end{array}$ \\
\hline \multirow{10}{*}{ China } & Nanjing, Jiangsu & NJ & 0.600 & 2.80 & $\mathrm{H} 1$ (4), $\mathrm{H} 3$ (1), H4 (1) \\
\hline & Jurong, Jiangsu & $J R$ & 0.000 & 0.000 & H9 (9) \\
\hline & Tongxiang, Zhejiang & $T X$ & 0.786 & 5.49 & $\mathrm{H} 1$ (1), $\mathrm{H} 4(4), \mathrm{H} 6(1), \mathrm{H} 8$ (1), $\mathrm{H} 10$ (1) \\
\hline & Haining, Zhejiang & $\mathrm{HN}$ & 0.250 & 1.17 & $\mathrm{H} 3(1), \mathrm{H} 4(7)$ \\
\hline & Chuzhou, Anhui & $\mathrm{CZ}$ & 0.561 & 3.11 & $\mathrm{H} 1$ (10), H2 (12), H3 (1) \\
\hline & Ganzhou, Jiangxi & GZ & 0.714 & 3.53 & $\mathrm{H} 1$ (10), $\mathrm{H} 2$ (4), H3 (4), $\mathrm{H} 4$ (3) \\
\hline & Huaihua, Hu'nan & $\mathrm{HH}$ & 0.000 & 0.000 & $\mathrm{H} 4(8)$ \\
\hline & Chengbu, Hu'nan & CB & 0.200 & 2.80 & H4 (9), H6 (1) \\
\hline & Sangzhi, Hu'nan & $\mathrm{sz}$ & 1.000 & 6.53 & $\mathrm{H} 1$ (1), H3 (1), H4 (1), H7 (1), H8 (1) \\
\hline & Wuhan, Hubei & WH & 0.000 & 0.000 & $\mathrm{H} 4(18)$ \\
\hline \multicolumn{3}{|c|}{ Regional average } & 0.732 & 5.22 & \\
\hline \multicolumn{2}{|l|}{ USA } & AM & 0.538 & 2.22 & $\mathrm{H} 3$ (4), H4 (9), H5 (1) \\
\hline \multirow{2}{*}{\multicolumn{2}{|c|}{$\begin{array}{l}\text { Australia } \\
\text { Population average }\end{array}$}} & AS & 0.363 & 2.11 & $\mathrm{H} 1$ (11), H2 (3) \\
\hline & & & 0.411 & 2.48 & \\
\hline \multicolumn{3}{|c|}{ Species average } & 0.737 & 5.80 & \\
\hline
\end{tabular}




\section{Genetic diversity and genetic structure}

At the species level, the cpDNA data revealed high estimates of haplotype diversity $\left(H_{D}\right.$ $=0.737)$ and nucleotide diversity $(\pi=0.00580)$. At the population level, estimates of haplotype diversity and nucleotide diversity were 0.411 and 0.00248 , respectively. Population SZ, which contained five haplotypes, was the population with the highest nucleotide diversity $(\pi=0.00653)$ and haplotype diversity $\left(H_{\mathrm{D}}=1.000\right)$, followed by population $\mathrm{HN}\left(H_{\mathrm{D}}=0.786, \pi=0.00549\right)$. In contrast, populations $\mathrm{JR}, \mathrm{HH}$, and $\mathrm{WH}$, which contained only one haplotype, exhibited the lowest levels of nucleotide and haplotype diversity ( 0 for both values, Table 3$)$. At the regional scale, the populations AM and AS exhibited lower levels of haplotype diversity $\left(H_{\mathrm{D}}=0.538\right.$ and 0.363 , respectively) and nucleotide diversity $(\pi=0.00222$ and 0.00211 , respectively) than Chinese populations $\left(H_{\mathrm{D}}=0.732, \pi=0.00522\right)$. AMOVA revealed that the majority of the genetic variation was between populations $\left(55.17 \%, F_{\mathrm{ST}}=0.551, \mathrm{P}<0.001\right)$, while the genetic variation within populations was $44.83 \%$ (Table 4$)$. The gene flow $\left(N_{\mathrm{m}}\right)$ was calculated as 0.408 .

Table 4. Results of analysis of molecular variance based on cpDNA sequences.

\begin{tabular}{l|c|c|c|c}
\hline Source of variation & Degrees of freedom & Sum of squares & $\begin{array}{c}\text { Percentage of variation } \\
\left(F_{\mathrm{ST}}\right)\end{array}$ & P value \\
\hline All populations & 11 & 169.868 & $55.17\left(F_{\mathrm{ST}}=0.551\right)$ & $<0.001$ \\
\hline Between populations & 132 & 131.820 & 44.83 & \\
\hline Within populations & 11 &
\end{tabular}

In the phylogenetic tree (Figure 2), the Z. schneideriana haplotypes were divided into two clades; Clade 1 consisted of $\mathrm{H} 3, \mathrm{H} 2, \mathrm{H} 1, \mathrm{H} 10, \mathrm{H} 4$, and $\mathrm{H} 5$, and Clade 2 contained $\mathrm{H} 8, \mathrm{H} 7, \mathrm{H} 6$, and $\mathrm{H} 9$.

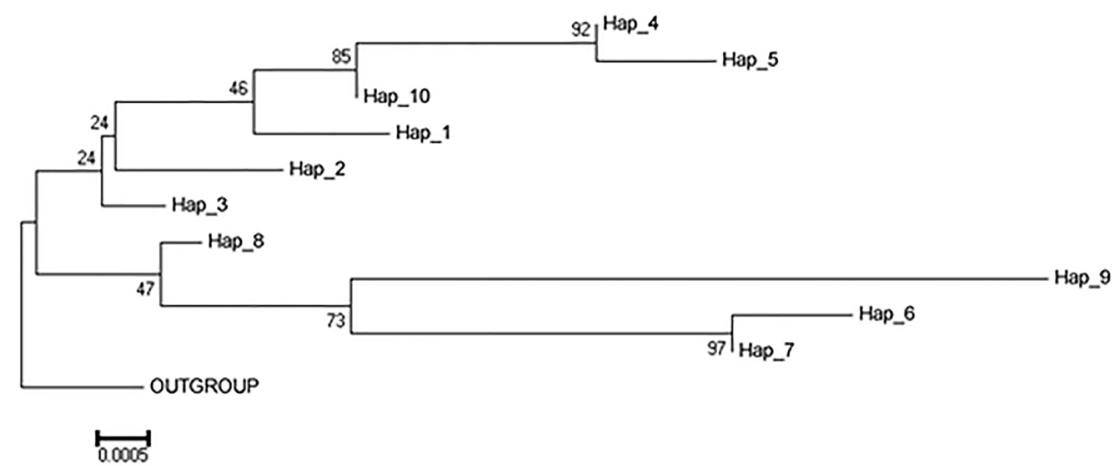

Figure 2. Phylogenetic relationships between 10 haplotypes of Zelkova schneideriana. Zelkova serrata was used as an outgroup. Numbers above/below branches are support values.

\section{DISCUSSION}

\section{Genetic diversity and population structure of Z. schneideriana}

Studies on the genetic diversity of $Z$. schneideriana have been relatively few in number. $A$ 
previous study that used ISSR markers found abundant genetic diversity in Z. Schneideriana from five populations in the Yunnan and Zhejiang Provinces (Liu et al., 2005). cpDNA haplotypes have seldom been used to detect the genetic diversity of Zelkova. In this study, we detected a high level of genetic diversity across 144 individuals from 12 populations of $Z$. schneideriana, with 10 different cpDNA haplotypes in two combined cpDNA regions ( $p s b \mathrm{~A}-\operatorname{trnH}$ and trnM-trnG). cpDNA analyses revealed a high level of genetic diversity in $Z$. schneideriana $\left(H_{D}=0.737, \pi=0.00580\right)$. The AM and AS populations were included in this study in order to trace their origins. Based on their haplotypes, the AM population might be derived from the $\mathrm{NJ}, \mathrm{HN}, \mathrm{GZ}$, and SZ populations; the AS population probably originated from the $G Z$ and $C Z$ populations. Except for the AM and AS populations, we estimated the genetic diversity of $Z$. schneideriana in China as 0.732 , which is similar to that found for other endemic Chinese woody plants, such as Pteroceltis tatarinowii (Ulmaceae, $\left.H_{\mathrm{D}}=0.76\right)(\mathrm{Li}$ et al., 2012) and Taxus wallichiana (Taxaceae, $H_{\mathrm{D}}=0.88$ ) (Gao et al., 2007), and is relatively high compared to the mean genetic diversity value estimated from cpDNA-based studies of 170 plant species $\left(H_{\mathrm{D}}=0.67\right)$ (Petit et al., 2005).

Genetic diversity varied between the populations. The most diverse populations (SZ and TX) contained five haplotypes, whereas populations $\mathrm{JR}, \mathrm{HH}$, and $\mathrm{WH}$ only contained one haplotype each $(\mathrm{H} 9, \mathrm{H} 4$, and $\mathrm{H} 4$, respectively). Low genetic diversity at the cpDNA level in some populations is always related to demographic events (Chiang et al., 2001). The haplotype network (Figure 1) suggests that the frequency of haplotype $\mathrm{H} 4$ may indicate an expansion event. Therefore, demographic events have played an important role in shaping the genetic diversity of Z. schneideriana.

Genetic variety at the cpDNA level mainly existed between populations $\left(F_{\mathrm{ST}}=0.551\right)$, which is similar to that previously reported in other endangered plants, such as Dalbergia nigra (Fabaceae, $F_{\mathrm{ST}}=0.624$ ) (Ribeiro et al., 2011) and Hymenaea courbaril (Fabaceae, $F_{\mathrm{ST}}=0.604$ ) (Ramos et al., 2009). Genetic differences between the populations may have been caused by the limited amount of gene flow $\left(N_{\mathrm{m}}=0.408\right)$, due to the species' limited seed dispersal (Fineschi et al., 2002).

\section{Conservation}

Considering the different levels of genetic diversity and population structure between the populations, both in situ and ex situ conservation and management strategies should be employed for Z. schneideriana in China.

The population from Sangzhi, Hunan, was the most suitable to be protected under an in situ conservation strategy. This population exhibited the highest level of genetic diversity (Table 2 ), which gives it the greatest potential for adaptation to future environmental change (Toro and Caballero, 2005). In addition, this population exhibited a highly mixed genetic structure (Figure 1 ), which represented five gene pools. Evidently, short-distance pollen dispersal requires a high population density and large population size to establish an adaptive and stable population to avoid losing genetic diversity in the future. Ex situ strategies are suitable for the AM, HN, JR, and TX populations, which contained the private haplotypes detected in this study (Figure 1). Since the majority of the genetic variation existed between populations, ex situ conservation and management strategies should focus on maximizing the collection of individuals from key populations, rather than from several populations. Therefore, collecting seeds from as many individuals as possible should preserve the genetic diversity of $Z$. schneideriana. 


\section{ACKNOWLEDGMENTS}

Research supported by the Science Research and Technology Development of Guangxi project "Genetic diversity analysis of Zelkova schneideriana and construction of seed production base for it" (Grant \#1598025-42), the Guangxi Youth Fund project "Fine-scale genetic structure of Zelkova schneideriana: based on evidence from population of Yachang Nature Reserve in Guangxi revealed by SSR markers" (Grant \#2013GXNSFBA019093), and the National Forestry Public Welfare Industry Research project "Provenance selection and rapid propagation in Zelkova schneideriana" (Grant \#200904011).

\section{REFERENCES}

Cao Y, Liu Z and Zhao H (2005). Preliminary investigation on the suitability of some deciduous broad-leaved trees in Beijing. J. Chin. Landscape Archit. 21: 62-64.

Chiang TY, Chiang YC, Chen YJ, Chou CH, et al. (2001). Phylogeography of Kandelia candel in East Asiatic mangroves based on nucleotide variation of chloroplast and mitochondrial DNAs. Mol. Ecol. 10: 2697-2710. http://dx.doi.org/10.1046/j.09621083.2001.01399.x

Clegg MT and Zurawski G (1992). Chloroplast DNA and the study of plant phylogeny: present status and future prospects. In: Molecular Systematics of Plants (Soltis PS, Soltis DE and Doyle JJ, eds.). Chapman and Hall, New York.

Clement M, Posada D and Crandall KA (2000). TCS: a computer program to estimate gene genealogies. Mol. Ecol. 9: 16571659. http://dx.doi.org/10.1046/j.1365-294x.2000.01020.x

Denk T and Grimm GW (2005). Phylogeny and biogeography of Zelkova (Ulmaceae sensu stricto) as inferred from leaf morphology, ITS sequence data and the fossil record. Bot. J. Linn. Soc. 147: 129-157. http://dx.doi.org/10.1111/j.10958339.2005.00354.x

Doyle JJ (1991). DNA protocols for plants. In: Molecular techniques in taxonomy (Hewitt GM and Johnston A, eds.). SpringerVerlag, Berlin, 283-293.

Drummond AJ, Ashton B, Cheung M, Heled J, et al. (2010). Geneious v 4.8. Accessible at http://www.geneious.com/.

Environmental Protection Department and Chinese Academy of Sciences (2013). Chinese Biodiversity Red Data Book. Higher Plants of China, Volume: 554.

Excoffier L, Smouse PE and Quattro JM (1992). Analysis of molecular variance inferred from metric distance among DNA haplotypes: application to human mitochondrial DNA restriction data. 131: 479-491.

Excoffier L, Laval G and Schneider S (2005). Arlequin (version 3.0): an integrated software package for population genetics data analysis. Evol. Bioinform. Online 1: 47-50.

Fineschi S, Anzidei M, Cafasso D, Cozzolino S, et al. (2002). Molecular markers reveal a strong genetic differentiation between two European relic tree species: Zelkova abelicea (Lam.) Boissier and Z. sicula Di Pasquale, Garfi \& Quézel (Ulmaceae). Conserv. Genet. 3: 145-153. http://dx.doi.org/10.1023/A:1015222230887

Fu L and Jin J (1992). Red Book of China- rare and endangered plants, volume I. Science Press, Beijing.

Gao LM, Möller M, Zhang XM, Hollingsworth ML, et al. (2007). High variation and strong phylogeographic pattern among cpDNA haplotypes in Taxus wallichiana (Taxaceae) in China and North Vietnam. Mol. Ecol. 16: 4684-4698. http://dx.doi. org/10.1111/j.1365-294X.2007.03537.x

Garfi G (1997). On the flowering of Zelkova sicula (Ulmaceae): additional description and comments. Plant Biosyst. 131: 137142. http://dx.doi.org/10.1080/11263504.1997.10654174

He P and Jin XL (2005). Chromosome numbers and karyotypes of three Zelkova species. Acta Bot. Yunnanica 27: $534-538$.

Kimura M (1980). A simple method for estimating evolutionary rates of base substitutions through comparative studies of nucleotide sequences. J. Mol. Evol. 16: 111-120. http://dx.doi.org/10.1007/BF01731581

Kress WJ, Wurdack KJ, Zimmer EA, Weigt LA, et al. (2005). Use of DNA barcodes to identify flowering plants. Proc. Natl. Acad. Sci. USA 102: 8369-8374.

Li X, Shao J, Lu C, Zhang X, et al. (2012). Chloroplast phylogeography of a temperate tree Pteroceltis tatarinowii (Ulmaceae) in China. J. Syst. Evol. 50: 325-333. http://dx.doi.org/10.1111/j.1759-6831.2012.00203.x

Librado P and Rozas J (2009). DnaSP v5: a software for comprehensive analysis of DNA polymorphism data. Bioinformatics 25: 1451-1452. http://dx.doi.org/10.1093/bioinformatics/btp187

Liu XC, Li YY and Chen SY (2005). Genetic diversity of Zelkova schneideriana from different populations by ISSR analysis. J. West China Forest. Sci 34: 43-47. 
Nei M, Tajima F and Tateno Y (1983). Accuracy of estimated phylogenetic trees from molecular data. II. Gene frequency data. J. Mol. Evol. 19: 153-170. http://dx.doi.org/10.1007/BF02300753

Newton AC, Allnutt TR, Gillies AC, Lowe AJ, et al. (1999). Molecular phylogeography, intraspecific variation and the conservation of tree species. Trends Ecol. Evol. (Amst.) 14: 140-145. http://dx.doi.org/10.1016/S0169-5347(98)01555-9

Petit RJ, Kremer A and Wagner DB (1993). Geographic structure of chloroplast DNA polymorphisms in European oaks. Theor. Appl. Genet. 87: 122-128. http://dx.doi.org/10.1007/BF00223755

Petit RJ, Duminil J, Fineschi S, Hampe A, et al. (2005). Comparative organization of chloroplast, mitochondrial and nuclear diversity in plant populations. Mol. Ecol. 14: 689-701. http://dx.doi.org/10.1111/j.1365-294X.2004.02410.x

Ramos AC, De Lemos-Filho JP and Lovato MB (2009). Phylogeographical structure of the neotropical forest tree Hymenaea courbaril (Leguminosae: Caesalpinioideae) and its relationship with the Vicariant Hymenaea stigonocarpa from Cerrado. J. Hered. 100: 206-216. http://dx.doi.org/10.1093/jhered/esn092

Ribeiro RA, Lemos-Filho JP, Ramos AC and Lovato MB (2011). Phylogeography of the endangered rosewood Dalbergia nigra (Fabaceae): insights into the evolutionary history and conservation of the Brazilian Atlantic Forest. Heredity (Edinb) 106: 46-57. http://dx.doi.org/10.1038/hdy.2010.64

Taberlet P, Fumagalli L, Wust-Saucy AG and Cosson JF (1998). Comparative phylogeography and postglacial colonization routes in Europe. Mol. Ecol. 7: 453-464. http://dx.doi.org/10.1046/j.1365-294x.1998.00289.x

Toro MA and Caballero A (2005). Characterization and conservation of genetic diversity in subdivided populations. Philos. Trans. R. Soc. Lond. B Biol. Sci. 360: 1367-1378. http://dx.doi.org/10.1098/rstb.2005.1680

Wright S (1949). The genetical structure of populations. Ann. Eugen. 15: 323-354. http://dx.doi.org/10.1111/j.1469-1809.1949. $\underline{\text { tb02451.x }}$

Zhang RQ, Yang J, Jin XL, Tang CF, et al. (2011). Dynamic activity of endogenous plant hormones in Zelkova schneideriana during the growth of seedlings. Nonwood Forest Res. 29: 1-5. 